\title{
Omega-3 polyunsaturated fatty acids and heart rate variability
}

\section{Jeppe Hagstrup Christensen*}

Department of Nephrology, Aalborg Hospital, Aarhus University Hospital, Aalborg, Denmark

\section{Edited by:}

George E. Billman, The Ohio State University, USA

\section{Reviewed by:}

George E. Billman, The Ohio State University, USA

Ruben Coronel, Academic Medical

Center, Netherlands

Hester M. Den Ruijter, University of

Amsterdam, Netherlands

\section{*Correspondence}

Jeppe Hagstrup Christensen, Department of Nephrology, Aalborg Hospital, Aarhus University Hospital, Molleparkvej 4, 9100 Aalborg,

Denmark.

e-mail: jeppe.hagstrup.christensen@ rn. $d k$
Omega-3 polyunsaturated fatty acids (PUFA) may modulate autonomic control of the heart because omega-3 PUFA is abundant in the brain and other nervous tissue as well as in cardiac tissue. This might partly explain why omega-3 PUFA offer some protection against sudden cardiac death (SCD). The autonomic nervous system is involved in the pathogenesis of SCD. Heart rate variability (HRV) can be used as a non-invasive marker of cardiac autonomic control and a low HRV is a predictor for SCD and arrhythmic events. Studies on HRV and omega-3 PUFA have been performed in several populations such as patients with ischemic heart disease, patients with diabetes mellitus, patients with chronic renal failure, and in healthy subjects as well as in children. The studies have demonstrated a positive association between cellular content of omega-3 PUFA and HRV and supplementation with omega-3 PUFA seems to increase HRV which could be a possible explanation for decreased risk of arrhythmic events and SCD sometimes observed after omega-3 PUFA supplementation. However, the results are not consistent and further research is needed.

Keywords: omega-3 polyunsaturated fatty acids, sudden cardiac death, autonomic function, heart rate variability

\section{INTRODUCTION}

Cardiac autonomic control is important in the pathogenesis of sudden cardiac death (SCD). Increased vagal activity is considered protective against SCD (Billman et al., 1982; Schwartz et al., 1984, 1992; Schwartz, 1998; Airaksinen, 1999) whereas sympathetic activity favors the development of cardiac arrhythmias (Task Force of the European Society of Cardiology, and the North American Society of Pacing and Electrophysiology, 1996). The modulation of autonomic control and a change in vagal tone and/or sympathetic tone may therefore be of major importance for the prevention of SCD (La Rovere et al., 1998).

Possible mechanisms for the protection against SCD from marine omega-3 polyunsaturated fatty acids (PUFA) are a topic in this issue of the Journal. Omega-3 PUFAs are components of membrane phospholipids throughout the body but particular docosahexaenoic acid (DHA) is highly concentrated in the central nervous system where it facilitates neuronal growth and has neuroprotective effects (Beltz et al., 2007; Innis, 2008; Niemoller and Bazan, 2010). As DHA is also abundant in cardiac tissue it is likely that omega-3 PUFA might modulate autonomic control of the heart. This paper reviews the studies on omega-3 PUFA and heart rate variability (HRV) in humans. HRV is a non-invasive marker of cardiac autonomic tone.

\section{HEART RATE VARIABILITY AND HOW CAN IT BE USED?}

During sinus rhythm heart rate (HR) and its inverse, the RRinterval, vary from beat-to-beat mainly in response to changes

Abbreviations: CRF, chronic renal failure; DHA, docosahexaenoic acid; DM, diabetes mellitus; EPA, eicosapentaenoic acid; IHD, ischemic heart disease; LF/HF, low frequency band/high-frequency band; MI, myocardial infarction; PUFA, polyunsaturated fatty acids; SCD, sudden cardiac death. in autonomic function. This beat-to-beat variation termed HRV is a non-invasive method to assess cardiac autonomic tone (Task Force of the European Society of Cardiology, and the North American Society of Pacing and Electrophysiology, 1996). HRV indices (and especially 24-h measurements) seems to be stable and free of placebo effects and HRV indices may thus be a useful tool in assessing the effect of intervention therapies on autonomic function of the heart (Task Force of the European Society of Cardiology, and the North American Society of Pacing and Electrophysiology, 1996).

Heart rate variability can be obtained during a short time period or from 24-h Holter recordings. It can be analyzed in the time domain and frequency domain, or by non-linear methods. Time domain indices (most often used) are based on normal-tonormal beat intervals (RR) but time and frequency domain HRV are closely associated (Kleiger et al., 1991, 2005; Bigger Jr. et al., 1992a).

Two forms of time domain HRV indices are used: (a) data derived directly from the RR interbeat intervals and (b) data derived from differences between successive RR-intervals. Interbeat interval measures are influenced by both short term (e.g., respiratory) and long-term (e.g., circadian) changes (Kleiger et al., 1992). Other time domain indices based on comparisons of lengths of adjacent cycles primarily reflects vagal modulation of the sinoatrial node (Kleiger et al., 1992). Abbreviations of some important time domain HRV indices are listed in Table 1.

Studies using frequency domain analyses (Task Force of the European Society of Cardiology, and the North American Society of Pacing and Electrophysiology, 1996; Akselrod et al., 1981; Pomeranz et al., 1985) assessed with spectral analysis have identified a low frequency (LF) band $(0.04-0.15 \mathrm{~Hz})$ reflecting both sympathetic and parasympathetic influences (Kingwell et al., 1994; 


\begin{tabular}{|c|c|c|}
\hline Variable & Units & Description \\
\hline $\mathrm{RR}$ & $\mathrm{ms}$ & Mean of all normal RR-intervals in the 24-h recording \\
\hline SDNN & $\mathrm{ms}$ & SD of all normal RR-intervals in the 24-h recording \\
\hline SDNN index & $\mathrm{ms}$ & $\begin{array}{l}\text { Mean of the SD of all normal RR-intervals for all } \\
5 \text {-min segments in the } 24 \text {-h recording }\end{array}$ \\
\hline SDANN index & $\mathrm{ms}$ & $\begin{array}{l}\text { SD of the mean of all normal RR-intervals measured } \\
\text { in successive } 5 \text {-min periods }\end{array}$ \\
\hline RMSSD & $\mathrm{ms}$ & $\begin{array}{l}\text { The square root of the mean of the sum of squares } \\
\text { of differences between adjacent RR-intervals in the } \\
\text { 24-h recording }\end{array}$ \\
\hline pNN50 & $\%$ & $\begin{array}{l}\text { Percentage of successive RR-interval differences } \\
>50 \mathrm{~ms} \text { during the } 24 \text {-h recording }\end{array}$ \\
\hline
\end{tabular}

Modified from Christensen (2003).

Srinivasan et al., 2002; Murray, 2003), and a high-frequency (HF) band $(0.15-0.5 \mathrm{~Hz})$, corresponding to respiratory frequency, attributed to parasympathetic influences (Akselrod et al., 1981; Pomeranz et al., 1985; Pagani et al., 1986). The LF/HF ratio has been considered to reflect cardiovascular sympathovagal balance (Pagani et al., 1988; Furlan et al., 1990), but the degree to which this ratio provides a comparison between sympathetic and parasympathetic influences has been questioned (Eckberg, 1997; Karemaker, 1999; Pivik and Dykman, 2004).

An attenuated HRV can reflect an increased sympathetic and/or decreased vagal modulation. These autonomic changes have been associated with an increased risk of malignant ventricular arrhythmias and SCD (Barron and Lesh, 1996; Schwartz, 1998; Airaksinen, 1999). Thus, a question of major importance is whether it is possible to increase HRV and if such an increase would improve clinical outcome. This is not fully answered yet but several pharmacological interventions resulting in an improved patient survival are associated with an increased HRV (Christensen, 2003).

The data from epidemiological and interventional studies on the possible beneficial effect of omega-3 PUFA on SCD makes it of importance whether such an effect can be partly explained by modulation of cardiac autonomic control as evaluated by HRV. Interventional studies on omega-3 PUFA and HRV in humans are summarized in Table 2, and the individual studies are dealt with in more detail below.

\section{OMEGA-3 PUFA AND HRV EARLY IN LIFE}

The incorporation of omega-3 PUFA in synaptic membranes could potentially influence the autonomic control of the heart. The progressive maturation of the autonomic nervous system during fetal and early life (Massin and von Bernuth, 1997) renders this period a sensitive time, during which supplementation with omega-3 PUFA might exert long-term effects on vagal tone and hence HRV. Studies on HRV and omega-3 supplementation in infants have been performed. In a study by Larnkjaer et al. (2006), no overall effect of omega-3 PUFA supplementation to lactating mothers was found on HRV in the 2.5-year-old offspring. However, in a gender specific analysis, a HRV increasing effect was found in girls.
In another Danish study, 83 healthy infants were randomized to omega-3 PUFA supplementation or no supplementation at 9-12 months of age (Lauritzen et al., 2008). In 57 infants, 0.5-h ECG recordings were successfully obtained before and after the intervention (3 months). Omega-3 PUFA supplementation raised erythrocyte omega-3 PUFA content $(p<0.001)$. An omega-3 PUFA $\times$ gender interaction was observed on mean RRinterval $(p=0.001)$ with a $6 \%$ longer mean RR-interval in fish-oilsupplemented boys $(p=0.007)$. Irrespective of gender, there was a positive association between the 9- and 12-month changes in RRinterval and erythrocyte omega-3 PUFA $(p<0.001)$. In infants with confirmed changes in erythrocyte omega-3 PUFA, mean RRinterval was found to be longer $(p=0.011)$ in the omega-3 PUFA supplemented group. This study concluded that omega-3 PUFA might affect heart rhythm in infants similar to that observed in some studies with adults.

In a study with a complex design Pivik et al. (2009) studied the effect of early infant diet including omega-3 PUFA on HR and HRV during the first 6 months of life. In the infants fed a DHA-deficient diet, higher HR and lower values for HRV measures were observed and the authors concluded that these findings indicated decreased parasympathetic tone in the DHA-deficient group. These effects appeared at 4 months of age and continued for the remaining 2 months of the study period, and the findings are consistent with suggestions that the 3- to 5-month postnatal interval may be an important period in the development of cardiovascular regulation. It should be emphasized that the acute and long-term clinical consequences of a slightly lower HR or improved HRV in infancy are, however, not known.

\section{OMEGA-3 PUFA AND HRV IN PATIENTS WITH HEART DISEASE}

Patients with ischemic heart disease (IHD) are at higher risk of SCD (Zipes and Wellens, 1998), and often have depressed HRV. The association between fish consumption, the content of omega3 PUFA in cell membranes and HRV was evaluated in 52 patients with a previous $\mathrm{MI}$ and a decreased left ventricular ejection fraction ( $\leq 0.40$; Christensen et al., 1997). Subjects who consumed fish at least once a week had a slightly (non-significant) higher SDNN compared to those never eating fish. These data may be in accordance with the data from Siscovick et al. (2000), and from the US Physicians Health Study (Albert et al., 1998) showing an approximately $50 \%$ reduction in the risk of SCD by eating fish once a week, However, these studies included patients without documented IHD although IHD is often the substrate for SCD (Zipes and Wellens, 1998).

It may be the actual membrane level of omega-3 PUFA that determines the susceptibility to develop arrhythmias and SCD (Siscovick et al., 1995; Albert et al., 2002). In the study above (Christensen et al., 1997), the content of omega-3 PUFA was measured in platelets and a close positive association was found between DHA and HRV. Such an association could indicate that supplementation with omega-3 PUFA would increase HRV and this hypothesis was tested in these high-risk patients (Christensen et al., 1996). The subjects were randomized to $5.2 \mathrm{~g}$ of omega- 3 PUFA daily ( 8 capsules) for 12 weeks or a comparable amount of olive oil. The HRV parameter SDNN increased significantly from 
Table 2 | Interventional studies in humans with omega-3 PUFA and heart rate variability measurements.

\begin{tabular}{|c|c|c|c|c|c|c|}
\hline Reference & Population & $\begin{array}{l}\text { Number } \\
\text { (total) }\end{array}$ & $\begin{array}{l}\text { Omega-3 } \\
\text { PUFA } \\
\text { (daily dose) }\end{array}$ & $\begin{array}{l}\text { Duration } \\
\text { of the } \\
\text { intervention }\end{array}$ & HRV indices & Result \\
\hline $\begin{array}{l}\text { Christensen et al. } \\
\text { (1996) }\end{array}$ & Coronary artery disease & 49 & $5.2 \mathrm{~g}$ & 12 weeks & Time domain (24-h) & + \\
\hline $\begin{array}{l}\text { Christensen et al. } \\
\text { (1998) }\end{array}$ & Dialysis patients & 29 & $5.2 \mathrm{~g}$ & 12 weeks & Time domain (24-h) & $(+)$ \\
\hline $\begin{array}{l}\text { Christensen et al. } \\
\text { (1999) }\end{array}$ & Healthy & 60 & 2.0 or $6.6 \mathrm{~g}$ & 12 weeks & Time domain (24-h) & + \\
\hline Villa et al. (2002) & Coronary heart disease & 10 & 3.0 or $6.0 \mathrm{~g}$ & 4 weeks & Time and frequency domain (24-h) & $(+)$ \\
\hline Geelen et al. (2003) & Healthy & 84 & $3.5 \mathrm{~g}$ & 12 weeks & Time and frequency domain $10 \mathrm{~min}$ & - \\
\hline Dyerberg et al. (2004) & Healthy males & & & 8 weeks & Time domain (24-h) & - \\
\hline Holguin et al. (2005) & Nursing home residents & 52 & $2.0 \mathrm{~g}$ & 4 months & $\begin{array}{l}6 \text { min repeated Time and } \\
\text { frequency domain }\end{array}$ & + \\
\hline Romieu et al. (2005) & Nursing home residents & 50 & $2.0 \mathrm{~g}$ & 5 months & $\begin{array}{l}6 \text { min repeated Time and } \\
\text { frequency domain }\end{array}$ & + \\
\hline O'Keefe et al. (2006) & Coronary artery disease & 18 & $1.5 \mathrm{~g}$ & $\begin{array}{l}2 \times 4 \text { months } \\
\text { (cross-over) }\end{array}$ & 76 min Time and frequency domain & + \\
\hline Hamaad et al. (2006) & Coronary artery disease & 38 & $1.0 \mathrm{~g}$ & 12 weeks & 76 min Time and frequency domain & - \\
\hline Larnkjaer et al. (2006) & Infants ( 2.5 years of age) & 69 & $4.5 \mathrm{~g}$ & $\begin{array}{l}\text { Given to the mothers } \\
\text { during } 4 \text { months of } \\
\text { lactation. The infants } \\
\text { were then examined } \\
\text { at } 2.5 \text { years of age }\end{array}$ & 30 min Time domain & $(+)$ \\
\hline Svensson et al. (2007) & Dialysis patients & 30 & $1.7 \mathrm{~g}$ & 12 weeks & $24 \mathrm{~h}$ Time domain & - \\
\hline Santini et al. (2007) & Type 2 diabetes & 15 & $1.0 \mathrm{~g}$ & 6 months & $24 \mathrm{~h}$ Frequency domain & $(+)$ \\
\hline Lauritzen et al. (2008) & Infants (9-12 months of age) & 83 & $0.9 \mathrm{~g}$ & 3 months & 30 min Time domain & $(+)$ \\
\hline Ninio et al. (2008) & Overweight adults & 65 & $6.0 \mathrm{~g}$ & 12 weeks & 20 min Frequency domain & + \\
\hline DeGiorgio et al. (2008) & Patients with epilepsy & 11 & $2.9 \mathrm{~g}$ & 12 weeks (cross-over) & 60 min Time domain & $(+)$ \\
\hline Pivik et al. (2009) & Infants (0-6 months) & 102 & Unknown & 6 months & $\begin{array}{l}5 \text { min (repeated) Frequency } \\
\text { domain }\end{array}$ & $(+)$ \\
\hline Carney et al. (2010) & $\begin{array}{l}\text { Depressed patients with } \\
\text { coronary artery disease }\end{array}$ & 37 & $2.0 \mathrm{~g}$ & 10 weeks & $24 \mathrm{~h}$ Frequency domain & + \\
\hline Hansen et al. (2010) & Prison inmates & 13 & $1.7 \mathrm{~g}$ & 23 weeks & 5 min Frequency domain & + \\
\hline Kim et al. (2011) & $\begin{array}{l}\text { Patients with mixed } \\
\text { dyslipidemia }\end{array}$ & 62 & $4.0 \mathrm{~g}$ & 6 weeks & $24 \mathrm{~h}$ Time and frequency domain & - \\
\hline
\end{tabular}

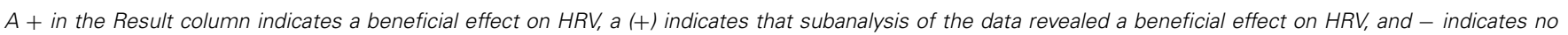
effect on HRV.

115 to $124 \mathrm{~ms}$ in the omega-3 PUFA group. Thus, this was the first study indicating that omega-3 PUFA could beneficially modulate cardiac autonomic control in IHD patients. Another study, by Russo et al. (1995) published 1 year earlier, has in previous papers been referred to as having measured HRV in hypertensive patients given omega-3 PUFA or placebo. They did not Holter monitor the patients nor did they obtain an ECG in these patients. However, they measured HR from ambulatory blood pressure recordings which is equal to HR measured four times per hour during the day and two times per hour during the night. They then reported the SD from these spot measurements as HRV. Thus, this interesting paper did not report HRV according to the usual definition where the beat-to-beat variation obtained in a continuous ECG recording is termed HRV.
Ischemic heart disease is the predominant underlying disease behind SCD (Zipes and Wellens, 1998). HRV was measured in 291 patients referred for coronary angiography due to suspected IHD and these measures were related to cell membrane and adipose tissue levels of omega-3 PUFA (Christensen et al., 2001a). Significant positive correlations were found between time domain HRV indices and levels of omega-3 PUFA, especially DHA. These associations remained significant also after controlling for several possible confounders.

In a smaller cross-over trial in 10 patients with IHD, HRV, and DHA correlated positively after dietary supplementation with omega-3 PUFA (Villa et al., 2002). A decrease in the low frequency band/high-frequency band (LF/HF) was found after having supplemented these patients with $6 \mathrm{~g}$ of omega-3 PUFA for 4 weeks. A 
low LF/HF is considered to reflect a favorable vagal predominance thus suggesting a protection against SCD.

O'Keefe Jr. et al. (2006) randomized 18 men with a history of MI and ejection fractions $<40 \%$ to omega-3 PUFA $(585 \mathrm{mg}$ of DHA and $225 \mathrm{mg}$ of EPA) or placebo for two 4-month periods in a cross-over design. At the end of each period, HR, HRV, and the rate of HR recovery after exercise were determined. Omega-3 PUFA supplementation decreased HR at rest and increased HRV only in the high-frequency (HF) band. Thus, these changes may also be consistent with an increase in vagal activity.

A smaller single blinded study in 38 post-MI patients using 20min ECG recordings did not show any changes in HRV indices in the time domain nor in the frequency domain after 3 months of supplementation with omega-3 PUFA or usual care (Hamaad et al., 2006). Nearly 70\% of these patients were on beta-adrenergic receptor blockers and/or ACE-inhibitor therapy, agents known to improve HRV. Furthermore, high-risk patients with ventricular ejection fractions $<40 \%$ and probably a low HRV, were excluded from this study. It is possible that the patients from this study would be the ones who would benefit most from omega-3 PUFA supplementation. The incorporation of omega-3 PUFA in phospholipids were not measured in this study and rather surprisingly the authors did not find any effect of omega-3 PUFA on serum triglycerides in these patients. A triglyceride lowering effect of omega-3 PUFA is one of the most consistent findings (Eslick et al., 2009) and in general such a finding indicates good compliance.

Nodari et al. (2009) investigated the effect of omega-3 PUFA on HRV in 44 patients with idiopathic dilated cardiomyopathy. These patients were without documented IHD. They were randomized to $1 \mathrm{~g}$ capsules of omega-3 PUFA or olive oil capsules for 6 months. Compliance was monitored by measuring the plasma levels of omega-3 PUFA before and after intervention. Frequency domain HRV indices were measured and the LF/HF ratio showed a $55 \%$ decrease in the treatment group versus a $54 \%$ increase in the placebo group. Thus, these results indicated a favorable shift in the cardiac autonomic balance.

Low intake of omega-3 PUFA is associated with depression and low HRV. Carney et al. (2010) therefore examined the effect of omega-3 PUFA on HRV in depressed patients with coronary heart disease. They randomized 72 patients to $2 \mathrm{~g}$ of omega- 3 PUFA daily or placebo on top of their antidepressive medication (sertraline) for 10 weeks. They measured the frequency domain HRV parameter very low frequency (VLF) before and after supplementation. VLF is strongly correlated to arrhythmic death after an acute MI (Bigger Jr. et al., 1992b). VLF did not change over time in the omega-3 PUFA group but decreased in the placebo group which led the authors to suggest that omega-3 PUFA may have prevented or slowed deterioration in cardiac autonomic function in these high-risk patients.

\section{OMEGA-3 PUFA AND HEART RATE VARIABILITY IN OTHER POPULATIONS \\ DIABETES MELLITUS}

The Framingham study was the first epidemiological report demonstrating a two to fourfold increased risk of angina pectoris and acute $\mathrm{MI}$ in diabetes mellitus (DM) patients (Kannel and McGee, 1979). These patients also have an excess post-MI mortality (Mak and Topol, 2000). Autonomic neuropathy involving the heart may be of importance and cardiac autonomic neuropathy carries an excess risk of mortality in patients with DM, including a high risk of SCD (Maser and Lenhard, 2005). HRV analysis is a well established tool in the early detection of autonomic neuropathy in patients with DM (Stein and Kleiger, 1999).

Heart rate variability was examined in 43 type 1 and 38 type 2 diabetes patients and related to omega-3 PUFA content in platelet membranes (Christensen et al., 2001b). In type $1 \mathrm{DM}$ patients HRV increased with increasing levels of DHA. Furthermore, this positive correlation between HRV and platelet DHA was more pronounced in patients with type $1 \mathrm{DM}$ solely receiving insulin therapy and without signs of diabetic complications. However, this study could not demonstrate a significant association between omega-3 PUFA and HRV in the patients with type 2 DM. In contrast, a small Italian study found that 6 months of omega-3 PUFA treatment in a group of 13 type $2 \mathrm{DM}$ patients partially improved HRV in the frequency domain (Santini et al., 2007).

Overweight persons with an increased risk of type 2 DM have an impaired HRV (Ninio et al., 2008). In a randomized, double-blind, parallel comparison, 65 overweight volunteers consumed DHA $1.56 \mathrm{~g} /$ day and EPA $0.36 \mathrm{~g} /$ day or sunflower-seed oil (placebo) for 12 weeks (Ninio et al., 2008). In 46 of these subjects HRV was assessed in the frequency domain using 20 min ECG recordings. Omega-3 PUFA supplementation improved HRV by increasing HF power, representing parasympathetic activity, and it also reduced HR at rest and during submaximal exercise. Thus, the authors concluded that dietary supplementation with DHArich fish oil reduced HR and modulated HRV in a favorable way in these overweight subjects with a high risk of IHD.

\section{CHRONIC RENAL FAILURE}

Approximately $50 \%$ of the mortality in patients with chronic renal failure (CRF) receiving dialysis is due to cardiovascular disease and it is estimated that SCD accounts for approximately 30\% of total mortality in patients with end stage renal disease (ESRD; Herzog et al., 2008). Cardiac autonomic dysfunction is very frequent in these patients (Barron and Lesh, 1996) with a high prevalence of ventricular arrhythmias. An attenuated HRV confers significant prognostic value in end stage renal failure patients (Chandra et al., 2011) as well as in other CRF patients (Oikawa et al., 2009). HRV may also identify patients at increased risk of SCD (Hayano et al., 1999).

Omega-3 PUFA may be beneficial for dialysis patients (Friedman and Moe, 2006) and could also have several beneficial effects in chronic kidney disease patients not treated with dialysis (Fassett et al., 2010). Three studies have examined the effect of omega3 PUFA on HRV in ESRD patients. The first study included 29 patients and examined the association between the content of omega-3 PUFA in granulocyte membranes and HRV (Christensen et al., 1998). Furthermore, the patients were randomly allocated to dietary supplementation with either $5.2 \mathrm{~g}$ of omega-3 PUFA or olive oil for 12 weeks. Only 17 patients completed the study (11 from the omega-3 PUFA group and 6 controls). This hampered comparisons between the two groups, but in the omega-3 PUFA group no increase in HRV was observed after supplementation 
whereas the mean RR-interval increased. These patients had very low HRV indices and also low levels of omega-3 PUFA at baseline. This is in accordance with recent data (Madsen et al., 2011). The narrow ranges of both HRV indices and omega-3 PUFA values may partly explain the lack of association between HRV and omega3 PUFA at baseline. Thus, an increase in the range of omega- 3 PUFA levels after dietary supplementation led to a significant positive correlation between omega-3 PUFA in granulocytes and the HRV parameter SDNN. Also, when the patients completing the trial were dichotomized according to their median SDNN, the omega-3 PUFA level was highest among those with the highest SDNN.

In an uncontrolled design, Fiedler et al. (2005) gave $1.2 \mathrm{~g}$ of omega-3 PUFA daily for 12 weeks to 11 hemodialysis patients. A number of cardiovascular risk factors were measured and the authors wrote they measured HRV. However, this variability was reported as 60-102 versus 61-105 beats/min before and after supplementation (NS). This was not a continuous recording of the RRinterval, and, therefore, does not provide a measurement of HRV.

In a subgroup of a larger population with ESRD and documented cardiovascular disease, Svensson et al. (2007), randomized 30 patients to $1.7 \mathrm{~g}$ of omega-3 PUFA daily or placebo (olive oil) for 3 months. This study could not find any effect on HRV by omega3 PUFA supplementation but a non-significant trend toward a reduced HR was observed in the omega-3 PUFA arm. It is evident that further studies are warranted regarding the effects of omega3 PUFA on HRV and autonomic modulation in these high-risk patients.

\section{HEALTHY SUBJECTS}

A low HRV seems to predict a poor outcome in healthy populations. In the "Men Born in 1913 Study" randomly selected men aged 50 years had HRV obtained from $10 \mathrm{~s}$ ECG strips at entry. During a 10-year follow-up an increased risk of death from IHD during a 10-year was observed in men with a decreased HRV (Tibblin et al., 1975). Also, in the Zutphen study, the 5-year ageadjusted relative risk of mortality for subjects with a low HRV measured from 25 to $30 \mathrm{~s}$ ECG strips was 2.1 in middle-aged and 1.4 in elderly men (Dekker et al., 1997), with an inverse association between HRV and the risk of SCD. Data from the Framingham study based on 2-h ECG recordings confirm the predictive value of a decreased HRV in the general population (Tsuji et al., 1994, 1996). Also, Molgaard et al. (1991) found an attenuated HRV in apparently healthy subjects subsequently suffering SCD.

The effect of dietary supplementation with omega-3 PUFA on HRV was examined in healthy subjects (Christensen et al., 1999). In this dose-response study, 60 healthy subjects were randomly divided into three groups receiving either (1) $2.0 \mathrm{~g}$ of omega3 PUFA, (2) $6.6 \mathrm{~g}$ of omega-3 PUFA, or (3) placebo (olive oil) daily for 12 weeks. Baseline examination revealed positive correlations between HRV indices and DHA in men, an observation also found by others (Brouwer et al., 2002). Overall, intervention with omega-3 PUFA had no effect on HRV, but if these healthy subjects were dichotomized according to their baseline median SDNN, dietary supplementation with omega-3 PUFA (both 2.0 and $6.6 \mathrm{~g}$ ) increased RR-interval in those subjects belonging to the lower median. By further stratifying these subjects according to gender, a dose-dependent increase in several HRV indices among men was seen whereas no effect was observed in women. The result from the male participants may emphasize the importance of the actual cellular membrane level of omega-3 PUFA as a major determinant of the risk of SCD (Siscovick et al., 1995; Albert et al., 2002).

Grimsgaard et al. (1998) also showed a reduction in HR (inversely related to RR) after supplementation with DHA to healthy men. Indeed, several studies have shown that omega-3 PUFA reduce HR (Mozaffarian et al., 2005), which may be of importance because an increased HR is strongly associated with a poor cardiovascular outcome (Palatini and Julius, 2004).

In contrast, a study including 84 middle-aged subjects who received $3.5 \mathrm{~g}$ of omega- 3 PUFA or placebo daily for 12 weeks found no effect of omega-3 PUFA on HRV obtained from short ECG recordings (10 min; Geelen et al., 2003). Compliance was measured in this study. The short recording time excluded the analysis of long-term diurnal variations in heart rhythm which could be of importance. Thus, it is unknown whether the vagal predominance during night time is modifiable by omega-3 PUFA.

A study by Dyerberg et al. (2004) looked at the effect of transand omega-3 PUFA on cardiovascular risk markers, among these HRV, in healthy males. The experimental fats were incorporated into bakery products and supplied daily. The omega-3 PUFA group received approximately $4 \mathrm{~g}$ of omega-3 PUFA daily. These subjects were healthy well-trained men with a high HRV at baseline and it was not possible to increase their HRV further during 8 weeks of supplementation.

\section{NURSING HOME RESIDENTS}

Another study addressing the effect of omega-3 PUFA on HRV included 52 residents from a Mexican nursing home (Holguin et al., 2005). A few of these patients had hypertension or IHD. Omega-3 PUFA $2 \mathrm{~g}$ daily or soy oil $2 \mathrm{~g}$ daily was supplied. HRV was assessed with 6-min readings obtained every other day for a 2-month run-in period and a 6-month supplementation period. Both supplements improved HRV, with the omega-3 PUFA supplementation being superior to soy oil capsules. There was no analysis of the differences in response between the groups. Nevertheless, this study lends support to the hypothesis that omega-3 PUFA may improve autonomic function.

In a quite similar setting and design as described above the same group included 50 nursing residents from a Mexican nursing home located in an environment where the residents were exposed to particulate matter (Romieu et al., 2005). Romieu et al. reported that omega-3 PUFA supplementation ( $2 \mathrm{~g}$ daily for 6 months) prevented HRV decline related to particulate matter exposure in this study population.

\section{OTHER SUBJECTS}

In a study from Norway 53 male (mean age 35 years) inmates from a prison were randomly assigned to intervention and control groups (Hansen et al., 2010). The intervention group received seafood (mainly fatty fish, $>8 \%$ fat) for dinner three times per week for a period of 6 months. Both groups were requested to eat their usual diet provided by the prison. Blood samples were collected and 5-min ECG recordings were obtained in order to 
analyze HRV (HF and LF power) before and after the 6-months study period. Due to various reasons only 13 subjects completed the trial but a significant reduction in the sympathovagal balance (decrease in LF/HF) was observed in the intervention group.

A Korean study evaluated the effects of omega-3 PUFA and simvastatin on lipids and lipoproteins and HRV in patients with mixed dyslipidemia (Kim et al., 2011). Nearly $70 \%$ of the patients had hypertension and many received antihypertensive medication. Sixty-two patients were randomized into two treatment groups given a combination treatment with $4 \mathrm{~g}$ of omega-3 PUFA and $20 \mathrm{mg}$ of simvastatin daily or a monotherapy of $20 \mathrm{mg}$ simvastatin for 6 weeks. After 6 weeks of intervention an $41 \%$ reduction in triglycerides concentration was observed in the omega-3 PUFA groups whereas no significant changes was seen for HRV indices in the time and the frequency domains (24-h recordings). This study had a relatively short intervention period and a longer period of supplementation could be of importance to reach steady state and thereby a possible effect on HRV.

Sudden unexpected death in epilepsy (SUDEP) is a major cause of death in epilepsy. It accounts for up to $20 \%$ of mortality and a smaller pilot study examined the effect of omega-3 PUFA supplementation to patients with intractable epilepsy (DeGiorgio et al., 2008). Eleven patients were given $2880 \mathrm{mg}$ omega-3 PUFA daily for 12 weeks and after a 6-week wash-out they were switched to soybean oil (placebo). A non-significant trend toward an increase in time domain HRV measures was observed in only in a few patients with a low baseline. Whether omega-3 PUFA improve HRV in people with epilepsy needs to be further examined in larger controlled clinical trials and it would also be of interest to know if omega-3 PUFA can reduce the high risk of SUDEP in epilepsy.

\section{POPULATION-BASED INVESTIGATIONS, OMEGA-3 PUFA, AND HRV}

A large study based on dietary omega-3 PUFA intake and HRV in a well-defined population was published a couple of years ago (Mozaffarian et al., 2008). More than 4000 subjects, aged $\geq 65$ years were included from the Cardiovascular Heart Study. Approximately $25 \%$ had DM and $20 \%$ had a history of IHD. The time domain HRV indices SDNN and RMSSD were measured from 10-s ECG recordings in 4263 subjects and in a group of 1361 participants, HRV in the time domain and in the frequency domain was derived from 24-h Holter recordings. In a subset of the subjects, plasma phospholipids levels of EPA and DHA was measured and these levels correlated significantly with the fish consumed ( $r=0.55, p<0.001)$. According to the fish intake, the participants were divided into five groups and in general, HRV was highest among the participants with the highest fish intake. From the subanalyses of HRV it was suggested that a high fish consumption was associated with an enhanced vagal activity and parasympathetic predominance. Thus, this population-based study seemed to confirm that omega-3 PUFA supplementation can modulate cardiac autonomic function in a favorable way.

Heart rate variability in relation to fruit, vegetable, and fish consumption was reported from the Veterans Administration Normative Aging Study (Park et al., 2009). HRV variables (4min recordings) were measured among 586 older men with 928 total observations from 2000 to 2007 . Dietary intake was evaluated with a self-administered semiquantitative food-frequency questionnaire and categorized into quartiles. No significant association was seen between HRV measures and intakes of other fruit and vegetables, vitamin $\mathrm{C}$, carotenoids, tuna and dark-meat fish, omega-3 PUFA. Thus, these data differed from the Cardiovascular Heart Study despite a similar intake of omega-3 PUFA in both study populations.

Inuit from Nunavik (northern Quebec) consume large amounts of fish and marine mammals. In a cross-sectional study the impact of omega-3 PUFA on resting HR and HRV among Nunavik Inuit adults was assessed also considering mercury exposure and other potential confounders (Valera et al., 2011). HRV data from 2-h Holter recordings was obtained in 181 adults $\geq 40$ years old ( 109 women and 72 men) living in the 14 coastal villages of Nunavik. Omega-3 PUFA levels were measured in membrane erythrocytes. In women, omega-3 PUFA was significantly associated with HRV indices also after controlling for several potential confounders whereas such associations could not be found in men.

\section{SUMMARY REMARKS}

Several studies have found a positive association between omega-3 PUFA and HRV (Christensen et al., 1997, 2001a,b; Brouwer et al., 2002; Mozaffarian et al., 2008; Valera et al., 2011) although data are not consistent (Park et al., 2009). Therefore, interventional studies are of importance and as shown in Table 2, 8 of these 20 studies have revealed results supporting a beneficial effect on HRV and in 7 other of these trials a subanalysis of the data pointed at an effect of omega-3 PUFA on HRV. However, 5 of the 20 trials could not confirm an effect on HRV.

The inconsistency of the trial findings could of course be due to a truly absent treatment effect. However, most studies showed some effect and, thus, other considerations should also be taken into account. It is evident that the populations examined are very heterogeneous ranging from infants to nursing home residents. However, despite this heterogeneity, these data still indicate beneficial effects in several trials.

The intervention studies are all with limited sample sizes making conclusions susceptible to statistical errors. Furthermore, the dose of omega-3 PUFA varied considerably as did the length of intervention. Both issues may be of importance because some data suggest a dose-dependent effect of omega-3 PUFA on HRV as well as a certain time may be needed to obtain a steady state of omega-3 PUFA concentration in the relevant tissue.

Of importance are also the different methods of assessing HRV. As seen in Table $2 \mathrm{HRV}$ data are derived from recordings ranging from $5 \mathrm{~min}$ to $24 \mathrm{~h}$. It is obvious that only $24 \mathrm{~h}$ recordings measure possible interactions on long-term diurnal variation in HRV. Whether time domain or frequency domain HRV variables are preferable is also an open question but both methods are used and sometimes in combination. Although some evidence (see above) support that the beat-to-beat variation in HR (HRV) reflects corresponding changes in cardiac parasympathetic regulation others have questioned the fact that HRV should reflect parasympathetic regulation (Taylor et al., 2001; Parati et al., 2006; Denver et al., 2007). Therefore, it is of importance to emphasize that HRV does not provide a quantitative measure of cardiac parasympathetic nerve activity (an accurate assessment of nerve activity can only be 
obtained from direct nerve recordings) but may provide a very limited qualitative index of changes in cardiac autonomic regulation. Thus, HRV data should always be interpreted with care.

Medications that have an impact on HRV could obscure any effect of omega-3 PUFA on HRV in patients with coronary heart disease or in ESRD patients. Compliance regarding the intake of omega-3 PUFA is also of importance and it is advised that compliance is assured by measuring the incorporation of these fatty acids into phospholipids either in serum or in cell membranes. Another issue is whether it is EPA or DHA or both that might beneficially affect HRV. Most data support DHA as the most important omega-3 PUFA when it comes to modify cardiac autonomic tone. This may be in accordance with the high concentration of DHA in nervous tissue.

Another question of importance is whether it is the HR reducing effect of omega-3 PUFA which is of most importance (Mozaffarian et al., 2005)? Such an effect could also be translated into an increased HRV. Recent data (animal study) from Billman and Harris (2011) has suggested that the HRV responses to omega-3 PUFA treatment are more consistent with reductions in the intrinsic pacemaker rate than with alterations in autonomic neural regulation. A previous animal study in rabbits (Verkerk et al., 2009) also found that omega-3 PUFA supplementation reduced pacemaker current and HR. One human study supports a direct effect of omega-3 PUFA on the heart (Harris et al., 2006). Harris et al. found that omega-3 PUFA supplementation reduced HR in cardiac transplant recipients. These hearts were of course denervated

\section{REFERENCES}

Airaksinen, K. E. (1999). Autonomic mechanisms and sudden death after abrupt coronary occlusion. Ann. Med. 31, 240-245.

Akselrod, S., Gordon, D., Ubel, F. A., Shannon, D. C., Berger, A. C., and Cohen, R. J. (1981). Power spectrum analysis of heart rate fluctuation: a quantitative probe of beat-to-beat cardiovascular control. Science 213, 220-222.

Albert, C. M., Campos, H., Stampfer, M. J., Ridker, P. M., Manson, J. E., Willett, W. C., and Ma, J. (2002). Blood levels of long-chain n-3 fatty acids and the risk of sudden death. N. Engl. J. Med. 346, 1113-1118.

Albert, C. M., Hennekens, C. H., O’Donnell, C. J., Ajani, U. A., Carey, V. J., Willett, W. C., Ruskin, J. N., and Manson, J. E. (1998). Fish consumption and risk of sudden cardiac death. JAMA 279, 23-28.

Barron, H. V., and Lesh, M. D. (1996). Autonomic nervous system and sudden cardiac death. J. Am. Coll. Cardiol. 27, 1053-1060.

Beltz, B. S., Tlusty, M. F., Benton, J. L., and Sandeman, D. C. (2007). Omega-3 fatty acids upregulate adult neurogenesis. Neurosci. Lett. 415, 154-158.
Bigger, J. T. Jr., Fleiss, J. L., Steinman, R. C., Rolnitzky, L. M., Kleiger, R. E., and Rottman, J. N. (1992a). Correlations among time and frequency domain measures of heart period variability two weeks after acute myocardial infarction. Am. J. Cardiol. 69, 891-898.

Bigger, J. T. Jr., Fleiss, J. L., Steinman, R. C., Rolnitzky, L. M., Kleiger, R. E., and Rottman, J. N. (1992b). Frequency domain measures of heart period variability and mortality after myocardial infarction. Circulation 85, 164-171.

Billman, G. E., and Harris, W. S. (2011). Effect of dietary omega-3 fatty acids on the heart rate and the heart rate variability responses to myocardial ischemia or submaximal exercise. Am. J. Physiol. Heart Circ. Physiol. 300, H2288-H2299.

Billman, G. E., Schwartz, P. J., and Stone, H. L. (1982). Baroreceptor reflex control of heart rate: a predictor of sudden cardiac death. Circulation 66, 874-880.

Brouwer, I. A., Zock, P. L., van Amelsvoort, L. G., Katan, M. B., and Schouten, E. G. (2002). Association between n-3 fatty acid status in blood and electrocardiographic predictors of arrhythmia risk in

and the reduction in HR could thereby not be mediated by a change in vagal tone.

Finally, it can be questioned whether the relatively modest changes in HRV induced by omega-3 PUFA really can explain the improved cardiovascular outcome such as a reduction in SCD. However, in this respect the possible effect on HRV is only one of several beneficial effects of omega-3 PUFA and it may be a combination of these effects which in the end materializes in the improved clinical outcome. In humans you can not isolate the other effects but you can chose to monitor only one of the effects.

\section{CONCLUSION}

Both nervous tissue and heart tissue have a high content of omega3 PUFA (especially DHA) and this may be consistent with the finding that this marine omega- 3 fatty acid may modulate cardiac autonomic function as assessed by HRV. Thus, omega-3 PUFA may modulate HRV both at the level of the autonomic nervous system and the heart. Most of the data in this review support that omega3 PUFA beneficially modulates cardiac autonomic control thereby possibly reducing the risk of arrhythmias. However, data are not consistent perhaps due to a large heterogeneity in the interventional trials such as small sample sizes, different populations, short duration of intake, limited periods of HRV assessment, or variable doses of omega-3 PUFA. Thus, further research is needed to confirm the possible beneficially effect of omega-3 PUFA on HRV. More work is also needed to understand the pathways through which omega-3 PUFA may improve HRV or reduce HR.

healthy volunteers. Am. J. Cardiol. 89, 629-631.

Carney, R. M., Freedland, K. E., Stein, P. K., Steinmeyer, B. C., Harris, W. S., Rubin, E. H., Krone, R. J., and Rich, M. W. (2010). Effect of omega3 fatty acids on heart rate variability in depressed patients with coronary heart disease. Psychosom. Med. 72, 748-754.

Chandra, P., Sands, R. L., Gillespie, B. W., Levin, N. W., Kotanko, P., Kiser, M., Finkelstein, F., Hinderliter, A., Pop-Busui, R., Rajagopalan, S., and Saran, R. (2011). Predictors of heart rate variability and its prognostic significance in chronic kidney disease. Nephrol. Dial. Transplant. doi: $10.1093 / \mathrm{ndt} / \mathrm{gfr} 340$

Christensen, J. H. (2003). n-3 Fatty acids and the risk of sudden cardiac death. Emphasis on heart rate variability. Dan. Med. Bull. 50, 347-367.

Christensen, J. H., Aaroe, J., Knudsen, N., Dideriksen, K., Kornerup, H. J., Dyerberg, J., and Schmidt, E. B. (1998). Heart rate variability and n3 fatty acids in patients with chronic renal failure - a pilot study. Clin. Nephrol. 49, 102-106.

Christensen, J. H., Christensen, M. S., Dyerberg, J., and Schmidt, E. B. (1999). Heart rate variability and fatty acid content of blood cell mem- branes: a dose-response study with n-3 fatty acids. Am. J. Clin. Nutr. 70, 331-337.

Christensen, J. H., Gustenhoff, P., Korup, E., Aaroe, J., Toft, E., Moller, J., Rasmussen, K., Dyerberg, J., and Schmidt, E. B. (1996). Effect of fish oil on heart rate variability in survivors of myocardial infarction: a double blind randomised controlled trial. BMJ 312, 677-678.

Christensen, J. H., Korup, E., Aaroe, J., Toft, E., Moller, J., Rasmussen, K., Dyerberg, J., and Schmidt, E. B. (1997). Fish consumption, n-3 fatty acids in cell membranes, and heart rate variability in survivors of myocardial infarction with left ventricular dysfunction. Am. J. Cardiol. 79, 1670-1673.

Christensen, J. H., Skou, H. A., Fog, L., Hansen, V., Vesterlund, T., Dyerberg, J., Toft, E., and Schmidt, E. B. (2001a). Marine n-3 fatty acids, wine intake, and heart rate variability in patients referred for coronary angiography. Circulation 103, 651-657.

Christensen, J. H., Skou, H. A., Madsen, T., Torring, I., and Schmidt, E. B. (2001b). Heart rate variability and n-3 polyunsaturated fatty acids in patients with diabetes mellitus. J. Intern. Med. 249, 545-552. 
DeGiorgio, C. M., Miller, P., Meymandi, S., and Gornbein, J. A. (2008). n-3 Fatty acids (fish oil) for epilepsy, cardiac risk factors, and risk of SUDEP: clues from a pilot, double-blind, exploratory study. Epilepsy Behav. $13,681-684$.

Dekker, J. M., Schouten, E. G., Klootwijk, P., Pool, J., Swenne, C. A., and Kromhout, D. (1997). Heart rate variability from short electrocardiographic recordings predicts mortality from all causes in middleaged and elderly men. The Zutphen Study. Am. J. Epidemiol. 145, 899-908. [See comments].

Denver, J. W., Reed, S. F., and Porges, S. W. (2007). Methodological issues in the quantification of respiratory sinus arrhythmia. Biol. Psychol. 74, 286-294.

Dyerberg, J., Eskesen, D. C., Andersen, P. W., Astrup, A., Buemann, B., Christensen, J. H., Clausen, P., Rasmussen, B. F., Schmidt, E. B., Tholstrup, T., Toft, E., Toubro, S., and Stender, S. (2004). Effects of trans- and n3 unsaturated fatty acids on cardiovascular risk markers in healthy males. An 8 weeks dietary intervention study. Eur. J. Clin. Nutr. 58, 1062-1070.

Eckberg, D. L. (1997). Sympathovagal balance: a critical appraisal. Circulation 96, 3224-3232.

Eslick, G. D., Howe, P. R., Smith, C., Priest, R., and Bensoussan, A. (2009). Benefits of fish oil supplementation in hyperlipidemia: a systematic review and meta-analysis. Int. J. Cardiol. 136, 4-16.

Fassett, R. G., Gobe, G. C., Peake, J. M., and Coombes, J. S. (2010). Omega-3 polyunsaturated fatty acids in the treatment of kidney disease. Am. J. Kidney Dis. 56, 728-742.

Fiedler, R., Mall, M., Wand, C., and Osten, B. (2005). Short-term administration of omega- 3 fatty acids in hemodialysis patients with balanced lipid metabolism. J. Ren. Nutr. 15, 253-256.

Friedman, A., and Moe, S. (2006). Review of the effects of omega-3 supplementation in dialysis patients. Clin. J. Am. Soc. Nephrol. 1, 182-192.

Furlan, R., Guzzetti, S., Crivellaro, W., Dassi, S., Tinelli, M., Baselli, G., Cerutti, S., Lombardi, F., Pagani, M., and Malliani, A. (1990). Continuous 24-hour assessment of the neural regulation of systemic arterial pressure and RR variabilities in ambulant subjects. Circulation 81, 537-547.

Geelen, A., Zock, P. L., Swenne, C. A., Brouwer, I. A., Schouten, E. G., and
Katan, M. B. (2003). Effect of n3 fatty acids on heart rate variability and baroreflex sensitivity in middle-aged subjects. Am. Heart J. 146, E4.

Grimsgaard, S., Bonaa, K. H., Hansen, J. B., and Myhre, E. S. (1998). Effects of highly purified eicosapentaenoic acid and docosahexaenoic acid on hemodynamics in humans. Am. J. Clin. Nutr. 68, 52-59.

Hamaad, A., Kaeng, L. W., Lip, G. Y., and MacFadyen, R. J. (2006). Oral omega n3-PUFA therapy (Omacor) has no impact on indices of heart rate variability in stable post myocardial infarction patients. Cardiovasc. Drugs Ther. 20, 359-364.

Hansen, A. L., Dahl, L., Bakke, L., Frøyland, L., and Thayer, J. F. (2010). Fish consumption and heart rate variability - preliminary results. $J$. Psychophysiol. 24, 41-47.

Harris, W. S., Gonzales, M., Laney, N., Sastre, A., and Borkon, A. M. (2006). Effects of omega-3 fatty acids on heart rate in cardiac transplant recipients. Am. J. Cardiol. 98, 1393-1395.

Hayano, J., Takahashi, H., Toriyama, T., Mukai, S., Okada, A., Sakata, S., Yamada, A., Ohte, N., and Kawahara, H. (1999). Prognostic value of heart rate variability during long-term follow-up in chronic haemodialysis patients with end-stage renal disease. Nephrol. Dial. Transplant. 14, 1480-1488.

Herzog, C. A., Mangrum, J. M., and Passman, R. (2008). Sudden cardiac death and dialysis patients. Semin. Dial. 21, 300-307.

Holguin, F., Tellez-Rojo, M. M., Lazo, M., Mannino, D., Schwartz, J., Hernandez, M., and Romieu, I. (2005). Cardiac autonomic changes associated with fish oil vs soy oil supplementation in the elderly. Chest 127, 1102-1107.

Innis, S. M. (2008). Dietary omega 3 fatty acids and the developing brain. Brain Res. 1237, 35-43.

Kannel, W. B., and McGee, D. L. (1979). Diabetes and cardiovascular disease. The Framingham study. JAMA 241, 2035-2038.

Karemaker, J. M. (1999). Autonomic integration: the physiological basis of cardiovascular variability. J. Physiol. 517,316

Kim, S. H., Kim, M. K., Lee, H. Y., Kang, H. J., Kim, Y. J., and Kim, H. S. (2011). Prospective randomized comparison between omega3 fatty acid supplements plus simvastatin versus simvastatin alone in Korean patients with mixed dyslipidemia: lipoprotein profiles and heart rate variability. Eur. J. Clin. Nutr. 65, 110-116.

Kingwell, B. A., Thompson, J. M., Kaye, D. M., McPherson, G. A., Jennings, G. L., and Esler, M. D. (1994). Heart rate spectral analysis, cardiac norepinephrine spillover, and muscle sympathetic nerve activity during human sympathetic nervous activation and failure. Circulation 90 , 234-240.

Kleiger, R. E., Bigger, J. T., Bosner, M. S., Chung, M. K., Cook, J. R., Rolnitzky, L. M., Steinman, R., and Fleiss, J. L. (1991). Stability over time of variables measuring heart rate variability in normal subjects. Am. J. Cardiol. 68, 626-630.

Kleiger, R. E., Stein, P. K., and Bigger, J. T. Jr. (2005). Heart rate variability: measurement and clinical utility. Ann. Noninvasive Electrocardiol. 10 88-101.

Kleiger, R. E., Stein, P. K., Bosner, M. S., and Rottman, J. N. (1992). Time domain measurements of heart rate variability. Cardiol. Clin. 10, 487-498.

La Rovere, M. T., Bigger, J. T. Jr., Marcus, F. I., Mortara, A., and Schwartz, P. J. (1998). Baroreflex sensitivity and heart-rate variability in prediction of total cardiac mortality after myocardial infarction. ATRAMI (autonomic tone and reflexes after myocardial infarction) Investigators. Lancet 351, 478-484.

Larnkjaer, A., Christensen, J. H., Michaelsen, K. F., and Lauritzen, L. (2006). Maternal fish oil supplementation during lactation does not affect blood pressure, pulse wave velocity, or heart rate variability in 2.5-y-old children. J. Nutr. 136, 1539-1544.

Lauritzen, L., Christensen, J. H., Damsgaard, C. T., and Michaelsen, K. F. (2008). The effect of fish oil supplementation on heart rate in healthy Danish infants. Pediatr. Res. 64, 610-614.

Madsen, T., Christensen, J. H., Svensson, M., Witt, P. M., Toft, E., and Schmidt, E. B. (2011). Marine n-3 polyunsaturated fatty acids in patients with endstage renal failure and in subjects without kidney disease: a comparative study. J. Ren. Nutr. 21, 169-175.

Mak, K. H., and Topol, E. J. (2000). Emerging concepts in the management of acute myocardial infarction in patients with diabetes mellitus. $J$. Am. Coll. Cardiol. 35, 563-568.

Maser, R. E., and Lenhard, M. J. (2005). Cardiovascular autonomic neuropathy due to diabetes mellitus: clinical manifestations, consequences, and treatment. J. Clin. Endocrinol. Metab. 90, 5896-5903.
Massin, M., and von Bernuth, G. (1997). Normal ranges of heart rate variability during infancy and childhood. Pediatr. Cardiol. 18, 297-302.

Molgaard, H., Sorensen, K. E., and Bjerregaard, P. (1991). Attenuated 24-h heart rate variability in apparently healthy subjects, subsequently suffering sudden cardiac death. Clin. Auton. Res. 1, 233-237.

Mozaffarian, D., Geelen, A., Brouwer, I. A., Geleijnse, J. M., Zock, P. L., and Katan, M. B. (2005). Effect of fish oil on heart rate in humans: a metaanalysis of randomized controlled trials. Circulation 112, 1945-1952.

Mozaffarian, D., Stein, P. K., Prineas, R. J., and Siscovick, D. S. (2008). Dietary fish and omega-3 fatty acid consumption and heart rate variability in US adults. Circulation 117, 1130-1137.

Murray, D. R. (2003). What is "heart rate variability" and is it blunted by tumor necrosis factor? Chest 123, 664-667.

Niemoller, T. D., and Bazan, N. G. (2010). Docosahexaenoic acid neurolipidomics. Prostaglandins Other Lipid Mediat. 91, 85-89.

Ninio, D. M., Hill, A. M., Howe, P. R., Buckley, J. D., and Saint, D. A. (2008). Docosahexaenoic acid-rich fish oil improves heart rate variability and heart rate responses to exercise in overweight adults. Br. J. Nutr. 100, 1097-1103

Nodari, S., Metra, M., Milesi, G. Manerba, A., Cesana, B. M., Gheorghiade, M., and Dei, C. L. (2009). The role of n-3 PUFAs in preventing the arrhythmic risk in patients with idiopathic dilated cardiomyopathy. Cardiovasc. Drugs Ther. 23, 5-15.

Oikawa, K., Ishihara, R., Maeda, T., Yamaguchi, K., Koike, A., Kawaguchi, H., Tabata, Y., and Itoh, H. (2009). Prognostic value of heart rate variability in patients with renal failure on hemodialysis. Int. J. Cardiol. 131, 370-377.

O'Keefe, J. H. Jr., Abuissa, H., Sastre, A., Steinhaus, D. M., and Harris, W. S. (2006). Effects of omega3 fatty acids on resting heart rate, heart rate recovery after exercise, and heart rate variability in men with healed myocardial infarctions and depressed ejection fractions. Am. J. Cardiol. 97, 1127-1130.

Pagani, M., Lombardi, F., Guzzetti, S., Rimoldi, O., Furlan, R., Pizzinelli, P., Sandrone, G., Malfatto, G. Dell'Orto, S., and Piccaluga, E. (1986). Power spectral analysis of heart rate and arterial pressure variabilities as a marker of sympathovagal interaction in man and conscious dog. Circ. Res. 59, 178-193. 
Pagani, M., Malfatto, G., Pierini, S., Casati, R., Masu, A. M., Poli, M., Guzzetti, S., Lombardi, F., Cerutti, S., and Malliani, A. (1988). Spectral analysis of heart rate variability in the assessment of autonomic diabetic neuropathy. J. Auton. Nerv. Syst. 23, 143-153.

Palatini, P., and Julius, S. (2004). Elevated heart rate: a major risk factor for cardiovascular disease. Clin. Exp. Hypertens. 26, 637-644.

Parati, G., Mancia, G., Di, R. M., and Castiglioni, P. (2006). Point: cardiovascular variability is/is not an index of autonomic control of circulation. J. Appl. Physiol. 101, 676-678.

Park, S. K., Tucker, K. L., O'Neill, M. S., Sparrow, D., Vokonas, P. S., $\mathrm{Hu}, \mathrm{H}$., and Schwartz, J. (2009). Fruit, vegetable, and fish consumption and heart rate variability: the Veterans Administration Normative Aging Study. Am. J. Clin. Nutr. 89, 778-786.

Pivik, R. T., and Dykman, R. A. (2004). Cardiovascular effects of morning nutrition in preadolescents. Physiol. Behav. 82, 295-302.

Pivik, R. T., Dykman, R. A., Jing, H., Gilchrist, J. M., and Badger, T. M. (2009). Early infant diet and the omega 3 fatty acid DHA: effects on resting cardiovascular activity and behavioral development during the first half-year of life. Dev. Neuropsychol. 34, 139-158.

Pomeranz, B., Macaulay, R. J., Caudill, M. A., Kutz, I., Adam, D., Gordon, D., Kilborn, K. M., Barger, A. C., Shannon, D. C., Cohen, R. J., and Benson, H. (1985). Assessment of autonomic function in humans by heart rate spectral analysis. Am. J. Physiol. 248, H151-H153.

Romieu, I., Tellez-Rojo, M. M., Lazo, M., Manzano-Patino, A., CortezLugo, M., Julien, P., Belanger, M. C., Hernandez-Avila, M., and Holguin, F. (2005). Omega-3 fatty acid prevents heart rate variability reductions associated with particulate matter. Am. J. Respir. Crit. Care Med. 172, 1534-1540.

Russo, C., Olivieri, O., Girelli, D., Azzini, M., Stanzial, A. M., Guarini, P., Friso, S., De, F. L., and Corrocher, R. (1995). Omega-3 polyunsaturated fatty acid supplements and ambulatory blood pressure monitoring parameters in patients with mild essential hypertension. J. Hypertens. 13, 1823-1826.

Santini, V., Ciampittiello, G., Gigli, F., Bracaglia, D., Baroni, A., Cicconetti, E., Verri, C., Gambardella, S., and Frontoni, S. (2007). QTc and autonomic neuropathy in diabetes: effects of acute hyperglycaemia and n-3 PUFA. Nutr. Metab. Cardiovasc. Dis. 17, 712-718.

Schwartz, P. J. (1998). The autonomic nervous system and sudden death. Eur. Heart J. 19(Suppl. F), F72-F80.

Schwartz, P. J., Billman, G. E., and Stone, H. L. (1984). Autonomic mechanisms in ventricular fibrillation induced by myocardial ischemia during exercise in dogs with healed myocardial infarction. An experimental preparation for sudden cardiac death. Circulation 69, 790-800.

Schwartz, P. J., LA Rovere, M. T., and Vanoli, E. (1992). Autonomic nervous system and sudden cardiac death. Experimental basis and clinical observations for post-myocardial infarction risk stratification. Circulation 85, 177-191.

Siscovick, D. S., Raghunathan, T., King, I., Weinmann, S., Bovbjerg, V. E., Kushi, L., Cobb, L. A., Copass, M. K., Psaty, B. M., Lemaitre, R., Retzlaff, B., and Knopp, R. H. (2000). Dietary intake of long-chain n-3 polyunsaturated fatty acids and the risk of primary cardiac arrest. Am. J. Clin. Nutr. 71, 208S-212S.

Siscovick, D. S., Raghunathan, T. E., King, I., Weinmann, S., Wicklund, K. G., Albright, J., Bovbjerg, V., Arbogast, P., Smith, H., Kushi, L. H., Cobb, L. A., Copass, M. K. Psaty, B. M., Lemaitre, R., Retzlaff, B., Childs, M., and Knopp, R.
H. (1995). Dietary intake and cell membrane levels of long-chain n-3 polyunsaturated fatty acids and the risk of primary cardiac arrest. JAMA 274, 1363-1367.

Srinivasan, K., Sucharita, S., and Vaz, M. (2002). Effect of standing on short term heart rate variability across age. Clin. Physiol. Funct. Imaging 22, 404-408.

Stein, P. K., and Kleiger, R. E. (1999). Insights from the study of heart rate variability. Annu. Rev. Med. 50, 249-261.

Svensson, M., Schmidt, E. B., Jorgensen, K. A., and Christensen, J. H. (2007). The effect of n-3 fatty acids on heart rate variability in patients treated with chronic hemodialysis. J. Ren Nutr. 17, 243-249.

Task Force of the European Society of Cardiology, and the North American Society of Pacing, and Electrophysiology. (1996). Heart rate variability: standards of measurement, physiological interpretation and clinical use. Circulation 93, 1043-1065.

Taylor, J. A., Myers, C. W., Halliwill, J. R., Seidel, H., and Eckberg, D. L. (2001). Sympathetic restraint of respiratory sinus arrhythmia: implications for vagal-cardiac tone assessment in humans. Am. J. Physiol. Heart Circ. Physiol. 280, H2804$\mathrm{H} 2814$.

Tibblin, G., Eriksson, C.-G., Bjurö, T., Georgescu, D., and Svärdsudd, C. (1975). Heart rate and heart rate variability a risk factor for the development of ischaemic heart disease (IHD) in the "men born in 1913 study" - a ten years follow-up. Med. Sci. Cardiovasc. Syst. Soc. Occup. 3, 95.

Tsuji, H., Larson, M. G., Venditti, F. J. Jr., Manders, E. S., Evans, J. C., Feldman, C. L., and Levy, D. (1996). Impact of reduced heart rate variability on risk for cardiac events. The Framingham Heart Study. Circulation 94, 2850-2855.

Tsuji, H., Venditti, F. J. Jr., Manders, E. S., Evans, J. C., Larson, M. G., Feldman,
C. L., and Levy, D. (1994). Reduced heart rate variability and mortality risk in an elderly cohort. The Framingham Heart Study. Circulation 90, 878-883.

Valera, B., Dewailly, E., NassourLaouan-Sidi, E., and Poirier, P. (2011). Influence of $n-3$ fatty acids on cardiac autonomic activity among Nunavik Inuit adults. Int. J. Circumpolar Health 70, 6-18.

Verkerk, A. O., den Ruijter, H. M., Bourier, J., Boukens, B. J., Brouwer, I. A., Wilders, R., and Coronel, R. (2009). Dietary fish oil reduces pacemaker current and heart rate in rabbit. Heart Rhythm. 6, 1485-1492.

Villa, B., Calabresi, L., Chiesa, G., Rise, P., Galli, C., and Sirtori, C. R. (2002). Omega-3 fatty acid ethyl esters increase heart rate variability in patients with coronary disease. Pharmacol. Res. 45, 475.

Zipes, D. P., and Wellens, H. J. (1998). Sudden cardiac death. Circulation 98, 2334-2351.

Conflict of Interest Statement: The author declares that the research was conducted in the absence of any commercial or financial relationships that could be construed as a potential conflict of interest.

Received: 28 September 2011; paper pending published: 04 October 2011; accepted: 31 October 2011; published online: 16 November 2011.

Citation: Christensen JH (2011) Omega3 polyunsaturated fatty acids and heart rate variability. Front. Physio. 2:84. doi: 10.3389/fphys.2011.00084

This article was submitted to Frontiers in Cardiac Electrophysiology, a specialty of Frontiers in Physiology.

Copyright (c) 2011 Christensen. This is an open-access article subject to a nonexclusive license between the authors and Frontiers Media SA, which permits use, distribution and reproduction in other forums, provided the original authors and source are credited and other Frontiers conditions are complied with. 